\title{
Competitive Retro-Cycloaddition Reaction in Fullerene Dimers connected through Pyrrolidino-pyrazolino
}

\author{
Rings. \\ Juan Luis Delgado, ${ }^{\dagger \neq}$ Silvia Osuna, ${ }^{\S}$ Pierre-Antoine Bouit, ${ }^{\ddagger}$ Roberto Martínez-Alvarez, ${ }^{\dagger}$ Eva \\ Espíldora, ${ }^{\dagger}$ Miquel Solà ${ }^{*}$ and Nazario Martín ${ }^{*+}+$ \\ ${ }^{\dagger}$ Departamento de Química Orgánica, Facultad de Ciencias Químicas, Universidad Complutense de \\ Madrid, 28040, Madrid, Spain. \\ * IMDEA-Nanociencia, Facultad de Ciencias, Módulo C-IX, $3^{a}$ planta, Ciudad Universitaria de \\ Cantoblanco, 28049 Madrid, Spain. \\ § Institut de Química Computacional and Departament de Quimica, Universitat de Girona, \\ E-17071 Girona, Catalonia, Spain.
}

miquel.sola@udg.cat,nazmar@quim.ucm.es 

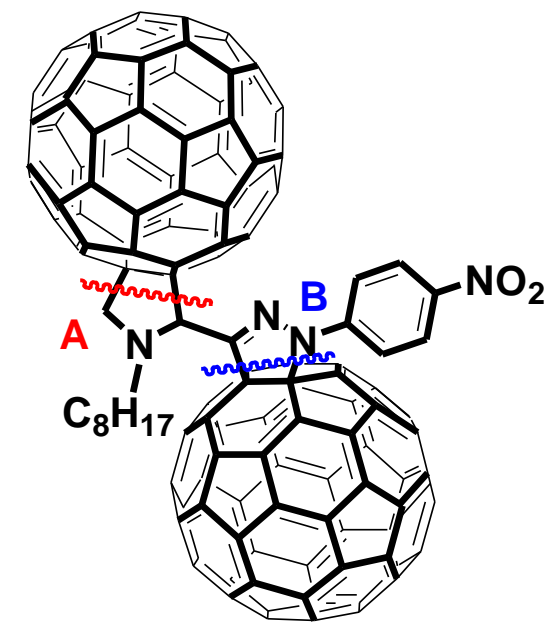

\section{A and / or B Retro-Cycloaddition?}

1a: $\mathrm{C}_{60}-\mathrm{C}_{60}$

$1 \mathrm{~b}: \mathrm{C}_{60}-\mathrm{C}_{70}$

1c: $\mathbf{C}_{70}-\mathbf{C}_{70}$

\section{$1 a$}

Abstract Competitive retro-cycloaddition in [60] and [70]fullerene homodimers (1a,1c) as well as [60]/[70]heterodimer (1b), linked through 2-pyrazolino-pyrrolidino bridges, has been studied by means of HPLC, mass spectrometry, and theoretical calculations at the density functional theory (DFT) level using the two-layered ONIOM approach. The results of these investigations indicate that the retrocycloaddition reaction of pyrrolidinofullerenes is favored compared to the retro-cycloaddition reaction of 2-pyrazolinofullerenes in compounds 1a-c. Evidences of the occurrence of this process have been observed both by HPLC and MS-MALDI, these findings being in good agreement with that predicted by theoretical calculations.

\section{Introduction}

Since fullerenes ${ }^{1}$ and other molecular carbon nanostructures ${ }^{2}$ were discovered, a remarkable effort has been devoted to their chemical modification. ${ }^{3}$ Moreover, owing to their exceptional electronic and geometrical characteristics, fullerenes represent an exceptional scenario for testing a wide variety of new reactions. ${ }^{4}$ Some of us have previously reported the thermally induced transition metal catalyzed quantitative retro-cycloaddition reaction of pyrrolidino[3,4:1,2]fullerenes ${ }^{5}$ as well as isoxazolino[3,4:1,2]fullerenes, ${ }^{6}$ and proved its convenience as a new and useful protection-deprotection 
protocol. ${ }^{5}$ Recently, this methodology has been also applied to induce the retro-cycloaddition process in 2-pyrazolino[3,4:1,2]fullerenes. ${ }^{7}$ The results of that study clearly indicated that $C$-substitution on the pyrazole ring plays an important role on the course of the reaction, as 1,3-diaryl-2pyrazolino[60]fullerenes are thermally stable under these conditions and form $\mathrm{C}_{60}$ in very low yields. In contrast, 1-aryl-3-alkyl-2-pyrazolino derivatives are more vulnerable to these experimental conditions, undergoing an efficient thermally induced transition metal catalyzed retro-cycloaddition reaction. In a previous manuscript, ${ }^{8}$ we have reported the preparation and photovoltaic applications of a new family of fullerene based compounds, namely, soluble [60] and [70]fullerene homodimers (1a,1c) and the [60]/[70]heterodimer (1b), linked through 2-pyrazolino-pyrrolidino bridges (Figure 1). These dimers represent the first example of covalently bonded pyrrolidino-pyrazolino-fullerene dimers, despite the fact that, pyrrolidinofullerenes ${ }^{9}$ and pyrazolinofullerenes, ${ }^{10}$ are well known in fullerene chemistry and have been extensively studied. In the present paper we report on the competitive retro-cycloaddition reaction that takes place in these dimers $(\mathbf{1 a - c})$, by means of thermally induced treatment in the presence of an excess of dipolarophile (maleic anhydride), as well as copper triflate $\left(\mathrm{CuOTf}_{2}\right)$. The competitive retrocycloaddition process that takes place on these dimers has also been studied by mass spectrometry and the experimental findings are underpinned by theoretical calculations at the density functional theory (DFT) level, using the two-layered ONIOM approach. 


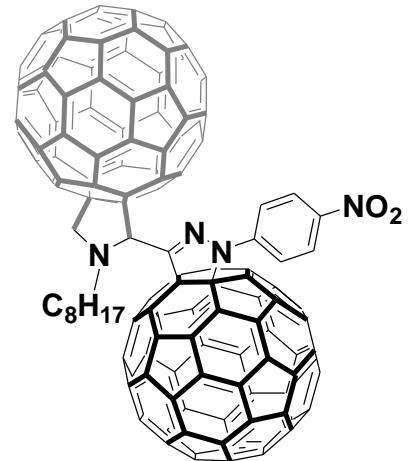

$1 \mathbf{a}$

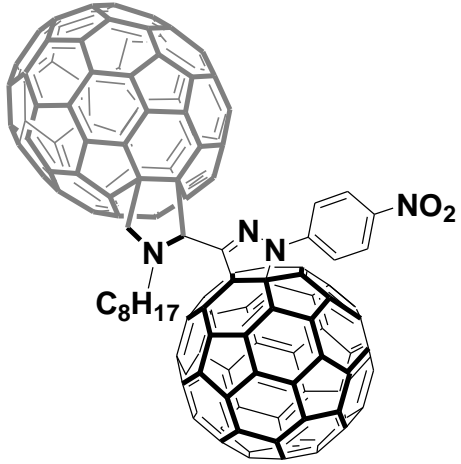

$1 \mathrm{~b}$

isomeric mixture

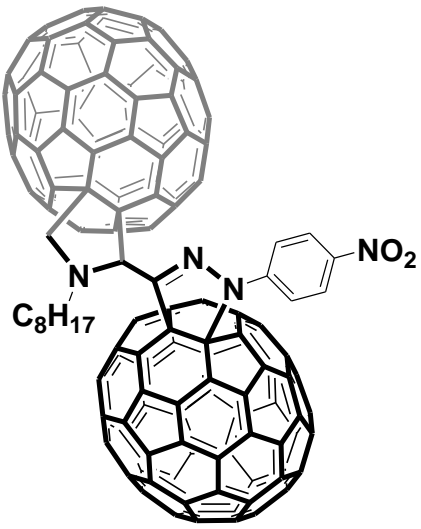

$1 \mathrm{c}$

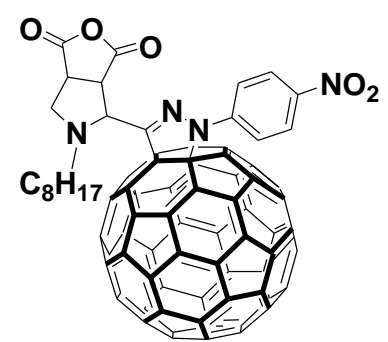

2

isomeric mixture

Figure 1: [60] and [70]fullerene homodimers $(\mathbf{1 a}, \mathbf{1 c})$ and the [60]/[70]heterodimer (1b), linked through 2-pyrazolino-pyrrolidino bridges. Thermally generated azomethyne ylide trapped by the maleic anhydride (2).

Analysis of the experimental and theoretical results obtained by these three different approaches reveals that the retro-cycloaddition occurs preferentially on the pyrrolidinofullerene moiety, due to the lower activation barrier and the slightly more favorable reaction energy for the entire process.

\section{Results and discussion.}

Thermal treatment In order to investigate the thermal stability of these dimers, compound 1a has been submitted to the same experimental conditions previously reported for other fullerene-fused pentagonal heterocyclic rings. ${ }^{5,6,7}$ Compound 1a was first heated at reflux in $o$-DCB for $24 \mathrm{~h}$, and then a small amount $(0.5 \mathrm{ml})$ of the reaction mixture was collected, diluted, and submitted to HPLC analysis (Table 1, $o$-DCB-24 h). The results of this experiment showed that pristine $\mathrm{C}_{60}$ was obtained in moderate yield (50\%) under thermal treatment. Then, we carried out the same experiment by adding a large excess (30 eq.) of maleic anhydride as an efficient dipolarophile in order to trap the in situ generated dipole (Table 1, MA-24h). Analysis of this experiment by HPLC showed that pristine $\mathrm{C}_{60}$ was obtained in a better yield $(66 \%)$ together with a new peak located at $11.25 \mathrm{~min}$. (toluene $1 \mathrm{~mL} / \mathrm{min}$.), which was identified by the detector of the HPLC as a fullerene-based compound. 


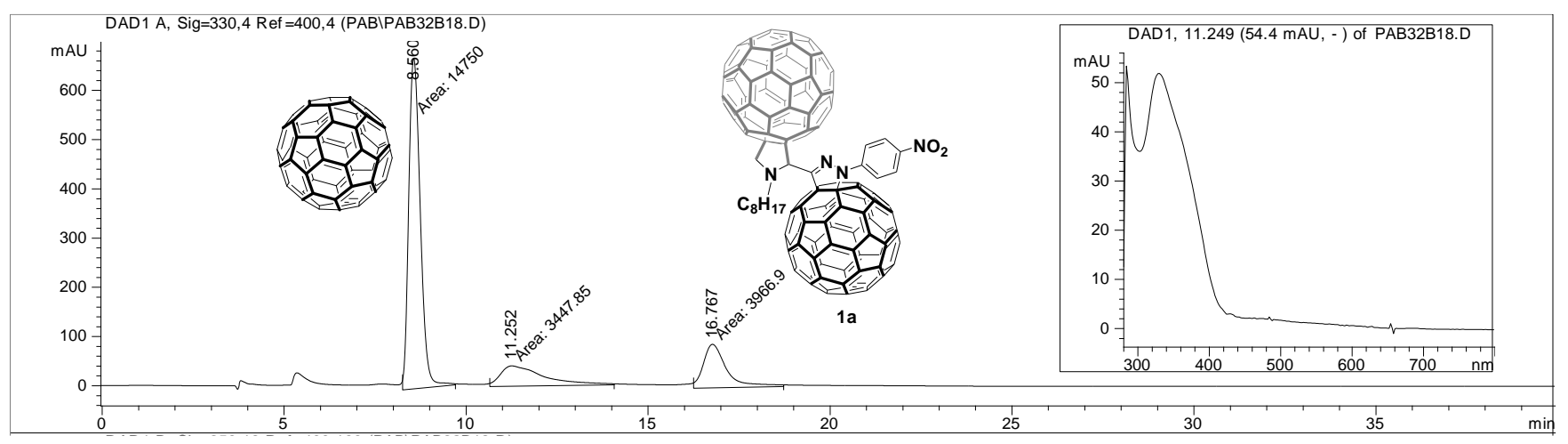

Figure 2: Chromatogram of the thermal retrocycloaddition of $1 \mathbf{a}$ in the presence of maleic anhydride (24h); The inset shows the UV-vis absorption spectrum of the new compound observed at $11.25 \mathrm{~min}$.

In order to shed some light on the nature of this new fullerene-based compound, we isolated a small amount of this new derivative by semi-preparative HPLC chromatography, and submited this sample to MALDI MS analysis. The recorded mass spectra, both in positive and negative mode of detection, do not exhibit the corresponding molecular ion proposed for the trapping of the thermally generated azomethyne ylide by the maleic anhydride (Compound 2, molecular weight $1134 \mathrm{Da}$ ). In contrast, a peak at $m / z 1104(\mathrm{M}-30 \mathrm{Da})$ and a fragment at $m / z 1060(1104-44 \mathrm{Da})$ were observed both in the negative and positive modes of detection. The structure of the proposed new derivative with a cyclic anhydride moiety supports the formation of both fragments. Thus, an elimination of $30 \mathrm{Da}$ (formaldehyde) and a subsequent loss of $44 \mathrm{Da}$ (carbon dioxide) explain the formation of these ions, thus indicating that the retro-cycloaddition of $\mathbf{1 a}$ takes place with trapping of the intermediate dipole (see SI). It is important to note that the mass spectra of cyclic anhydrides are known to give small or negligible molecular ion peaks but produce abundant peaks due to $\mathrm{CO}_{2}$ elimination. ${ }^{11}$ The fragmentation pattern of this new derivative can be therefore considered as a proof of the proposed structure. This conclusion is, indeed, well supported by our previous research findings: when performing the retro-cycloaddition study with different 2-pyrazolinofullerenes, we were not able to observe the trapped nitrile-imine species in any case. $^{7}$ On the contrary, dealing with fulleropyrrolidines, the retro-cycloaddition process is more favored, and efficient trapping of the thermally generated azomethine ylide has recently been described. ${ }^{12}$ 
Table 1: Experimental conditions used for the retro-cycloaddition reaction undergone by the 2pyrazolino-pyrrolidino[60]fullerenes, ${ }^{a}$ and formation of pristine $\mathrm{C}_{60}(\%)$ determined by HPLC.

\begin{tabular}{|c|c|c|c|c|}
\hline Entry & Compound & $\begin{array}{c}\text { Experimental } \\
\text { Conditions }\end{array}$ & $\begin{array}{c}\mathrm{C}_{60} \\
(\% \text { Yield })\end{array}$ & $\begin{array}{c}\mathrm{C}_{70} \\
\text { (\% Yield) }\end{array}$ \\
\hline 1 & 1a & $o$-DCB-24 h. & 50 & - \\
\hline 2 & $1 \mathbf{a}$ & MA-24 h. & 66 & - \\
\hline 3 & $1 \mathbf{a}$ & $\mathrm{CuTf}_{2}-24 \mathrm{~h}$. & 58 & - \\
\hline 4 & 1a & MA-CuTf $2-24$ h. & 67 & - \\
\hline 5 & $1 b$ & MA-24 h. & 11 & 60 \\
\hline 6 & $1 c$ & MA-24 h. & - & 84 \\
\hline
\end{tabular}

${ }^{a}$ All the reactions were performed in $o$-DCB at reflux; $\mathrm{MA}=30$ eq. of maleic anhydride; $\mathrm{CuTf}_{2}=1$ equiv. of copper triflate.

Then, we performed the same experiment but adding copper triflate, a metal Lewis acid, in order to find out if a possible coordination with the nitrogen atoms could activate the retro-cycloaddition reaction. (Table 1, entry 3). The results of this experiment showed that pristine $\mathrm{C}_{60}$ was obtained in $58 \%$ yield, a value that resembles that obtained with simple thermal treatment, being therefore, the influence of copper triflate, scarce or negligible on the retrocycloaddition process. When the experiment was performed in the presence of maleic anhydride (30 eq.) and copper triflate (1 eq.), (Table 1, entry 4) a similar result for the retro-cycloaddition of compound 1a, (67\%) to that of entry 2 was observed. The appearance of the new peak at $11.25 \mathrm{~min}$, was also detected, thus confirming the formation of the trapped azomethyne ylide in the presence of maleic anhydride.

The experiments performed on derivative 1a, suggest that the best condition to trap the dipole and induce thermal retro-cycloaddition of fulleropyrrolidines is to add a large excess of dipolarophile. Therefore, we carried out analogous experiments with derivatives $\mathbf{1 b}$ and $\mathbf{1 c}$. Derivative $\mathbf{1 b}$ is especially 
important in order to determine which retro-process is favored, since both fullerene units $\left(\mathrm{C}_{60}\right.$ and $\left.\mathrm{C}_{70}\right)$ are present in this compound. Interestingly when compound $\mathbf{1 b}$ was heated at reflux in the presence of maleic anhydride (30 eq.), $\mathrm{C}_{70}$ was obtained in a larger amount $(60 \%)$ than that observed for $\mathrm{C}_{60}(11 \%)$, providing strong evidence that the retro-cycloaddition of fulleropyrrolidines is more favored compared to the retrocycloaddition of 2-pyrazolinofullerenes. Moreover, we also observed the appearance of the peak located at $11.25 \mathrm{~min}$. (toluene $1 \mathrm{~mL} / \mathrm{min}$.), confirming the formation of the trapped azomethine ylide in the presence of maleic anhydride. The same experiment carried out with derivative 1c showed that $\mathrm{C}_{70}$ was generated in good yield $(84 \%)$ together with other peaks that display UV-vis spectra typical for a $\mathrm{C}_{70}$ based compound, most likely due to the trapping of the generated azomethine ylide.

Mass spectrometry. The mass spectrum of an organic compound provides two types of complementary information: one is the knowledge of the molecular weight and formula based on the molecular ion, and the second one is the determination of the structure on the grounds of the fragmentation pattern. Since fragmentation is a chemical process resulting in the bond breaking, the spectrometric fragmentation is sometimes closely related to chemical degradation processes. ${ }^{13}$ Cycloadditions and their corresponding retroprocesses are one of the most classical reactions which can be investigated either chemically or under the mass spectrometric point of view. The well known retroDiels-Alder (RDA) reaction originating a mass spectrometer was first recognized by Biemann ${ }^{14}$ and is actually one of the most investigated spectrometric reactions. ${ }^{15}$ Ionization methods such as electronimpact-ionization (EI) are hardly used in the fullerene mass spectrometry field. ${ }^{16}$ In contrast, soft ionization methods, especially matrix-assisted laser desorption/ionization (MALDI) and electrospray ionization (ESI) are widely used, even overcoming problems like insolubility and/or degradation of the sample. ${ }^{17}$

In a previous study by some of us, we reported that the thermally induced retro-cycloaddition reaction in isoxazolino[60]- and [70]-fullerene derivatives can also be observed from the molecular ions generated by ESI-MS. ${ }^{6 a}$ On the other hand, $N$-methyl and $N$-unsubstituted pyrrolidinofullerenes undergo the thermal retrocycloaddition affording pristine fullerene. ${ }^{5}$ In contrast, $N$-benzoyl pyrrolidinofullerenes 
do not give this reaction. ${ }^{12}$ The study of the collision-induced dissociation (CID) mass spectra of the molecular ions generated from these molecules under ESI conditions also supports these findings. ${ }^{18} 2$ Pyrazolino[4,5:1,2][60]fullerenes also undergo a thermal retrocycloaddition, ${ }^{7 b}$ and evidence of this process can be obtained from the CID-ESI mass spectra of these compounds, which form $\mathrm{C}_{60}$ in the main fragmentation pathway of the corresponding molecular ions. ${ }^{18}$

We have investigated the HRMS MALDI mass spectra of compounds 1-3 in order to verify if the observed thermal retro-cycloadditions also take place when these reactions are induced in the mass spectrometer. Thus, the homodimer 1a exhibits a molecular ion $[\mathrm{M}+\mathrm{H}]^{+}$at $m / z 1757.19720$ which eliminates $720 \mathrm{Da}\left(\mathrm{C}_{60}\right)$ to form a fragment at $\mathrm{m} / z 1037.204([\mathbf{6 0}] \mathbf{3 a})$ as the main fragmentation through a retro-cycloaddition process. However, the existence of an open 1,3 dipole instead of an aziridine ring cannot be ruled out. A second observed fragment at $\mathrm{m} / \mathrm{z} 874.153$ ([60]3b) which corresponds to a formula $\mathrm{C}_{70} \mathrm{H}_{20} \mathrm{~N}$ clearly indicates a cleavage of the heterocycle bridge with charge retention on the pyrrolidinofullerene moiety (Scheme 1).

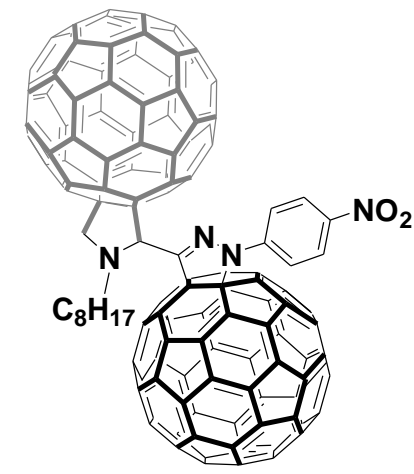

$1 \mathrm{a}$

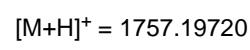

$$
\mathrm{C}_{137} \mathrm{H}_{25} \mathrm{~N}_{4} \mathrm{O}_{2}
$$
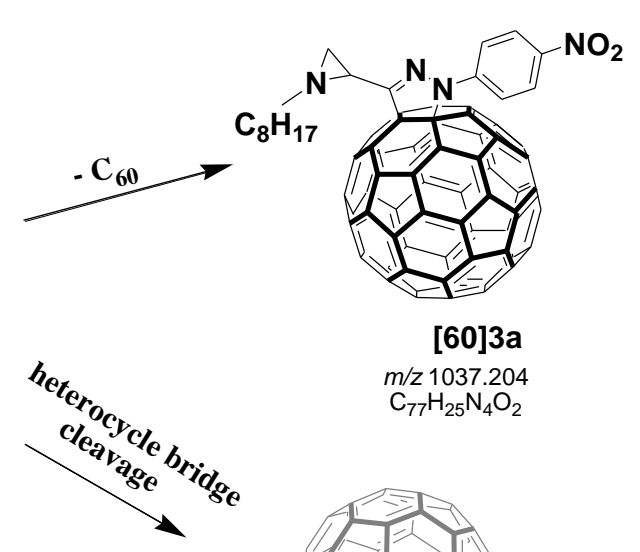

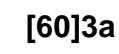

$\mathrm{m} / \mathrm{z} 1037.204$

$\mathrm{C}_{77} \mathrm{H}_{25} \mathrm{~N}_{4} \mathrm{O}_{2}$

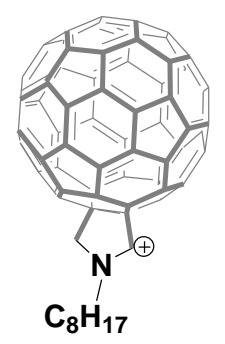

[60]3b

$m / z 874.153$
$\mathrm{C}_{70} \mathrm{H}_{20} \mathrm{~N}$

Scheme 1: Mass spectrum fragmentation pattern of homodimer 1a. 
Thus, now the question is to know in which heterocycle the retro-cycloaddition takes place. The mass spectrum of heterodimer $\mathbf{1 b}$ shows a molecular ion $[\mathrm{M}+\mathrm{H}]^{+}$at $m / z 1877.19720$ which undergoes a retrocycloaddition reaction with loss of $840 \mathrm{Da}\left(\mathrm{C}_{70}\right)$ leading to the formation of a fragment at $\mathrm{m} / \mathrm{z} 1037.307$ ([60]3a), identical to the fragment obtained from 1a. This result can only be explained assuming that the retro-cycloaddition takes place easier on the pyrrolidinofullerene moiety. The cleavage of the heteroring bridge is also observed in this case provoking the formation of a fragment at $\mathrm{m} / z$ 994.160 ([70]3b) with a formula $\mathrm{C}_{80} \mathrm{H}_{20} \mathrm{~N}$ which indicates that the charge retention occurs in the pyrrolidinofullerene moiety. The mass spectrum of 1c confirms these facts. The molecular ion $[\mathrm{M}+\mathrm{H}]^{+}$at $\mathrm{m} / z \quad 1997.19720$ $\left(\mathrm{C}_{157} \mathrm{H}_{25} \mathrm{~N}_{4} \mathrm{O}_{2}\right)$ eliminates $\mathrm{C}_{70}$ to form a fragment at $\mathrm{m} / \mathrm{z} 1157.205$ ([70]3a) resulting from the retrocycloaddition on the pyrrolidinofullerene substructure with elimination of $\mathrm{C}_{70}$. Moreover, the cleavage of the heteroring bridge yields a fragment at $\mathrm{m} / \mathrm{z} 994.160$ ([70]3b) identical to the ion found for the cleavage of $\mathbf{1 b}$.

\section{Theoretical calculations}

Under thermal treatment and in the presence of reagent excess of some dipolarophile such as maleic anhydride, pyrrolidino[3,4:1,2][60]fullerenes can efficiently revert back to [60]fullerene and azomethine ylide in what is called the retro-Prato reaction. ${ }^{5}$ Experimentally, pyrrolidinofullerenes revert to the initial reactants $\left(\mathrm{C}_{60}+1,3\right.$-dipole $)$ at lower temperature than pyrazolinofullerenes do. ${ }^{12}$ To provide some insight into this different behavior, in this work, we have theoretically explored the reaction mechanism for the retro-1,3-dipolar cycloaddition that leads to nitrile imine and $\mathrm{C}_{60}$. The results obtained have been compared to the previously studied mechanism for the same retro-Prato reaction involving azomethine ylide as the 1,3 -dipole. ${ }^{12}$ In this previous work, ${ }^{12}$ the retro-Prato reaction of $\mathrm{N}$ methylpyrrolidinofullerene to give $\mathrm{C}_{60}$ and azomethine ylide was assessed in the presence of maleic anhydride as a dipolarophile. Figure 3 shows the relative energies and Gibbs free energies of the transition states (TSs) and products for the most favorable mechanism. Calculations showed that the presence of maleic anhydride did not improve the efficiency of the reaction by reducing the barrier of the 
retro-cycloaddition reaction. However, the retro-Prato reaction was clearly favored as the final 1,3dipole generated was stabilized through reaction with maleic anhydride, converting the overall reaction from highly endothermic (the reaction energy for the retro-Prato reaction was $53.2 \mathrm{kcal} \mathrm{mol}^{-1}$ ) to substantially exothermic (in the presence of maleic anhydride, the reaction energy became $-16.4 \mathrm{kcal}$ $\mathrm{mol}^{-1}$ ) (see Figure 3). Therefore, the most favorable mechanism was obtained when the assistance of the dipolarophile was not produced along the whole reaction path, but only at the final stage of the reaction. The retro-cycloaddition presented a high energy barrier of $45.4 \mathrm{kcal} \mathrm{mol}^{-1}\left(\Delta \mathrm{G}^{\ddagger}=39.2 \mathrm{kcal} \mathrm{mol}^{-1}\right)$ which was smaller than the reaction energy found $\left(53.1 \mathrm{kcal} \mathrm{mol}^{-1}, \Delta \mathrm{G}_{\mathrm{r}}=34.0 \mathrm{kcal} \mathrm{mol}^{-1}\right)$. However, no minimum structure was located indicating the existence of a very shallow minimum close to the TS. Once the retro-cycloaddition was produced $(4 \mathbf{a}+\mathbf{5} \rightarrow \mathbf{C} \mathbf{6 0}+\mathbf{6 a}+\mathbf{5})$, the formed azomethine ylide reacted immediately with maleic anhydride generating the final product $7 \mathbf{a}\left(\mathbf{C}_{60}+\mathbf{6 a}+\mathbf{5} \rightarrow \mathbf{C} 6 \mathbf{6 0}+7 \mathbf{a}\right.$, see Figure 3). The latter process was barrierless as neither a TS nor an intermediate could be located during the approach of $\mathbf{6 a}$ and $\mathbf{5}$. 


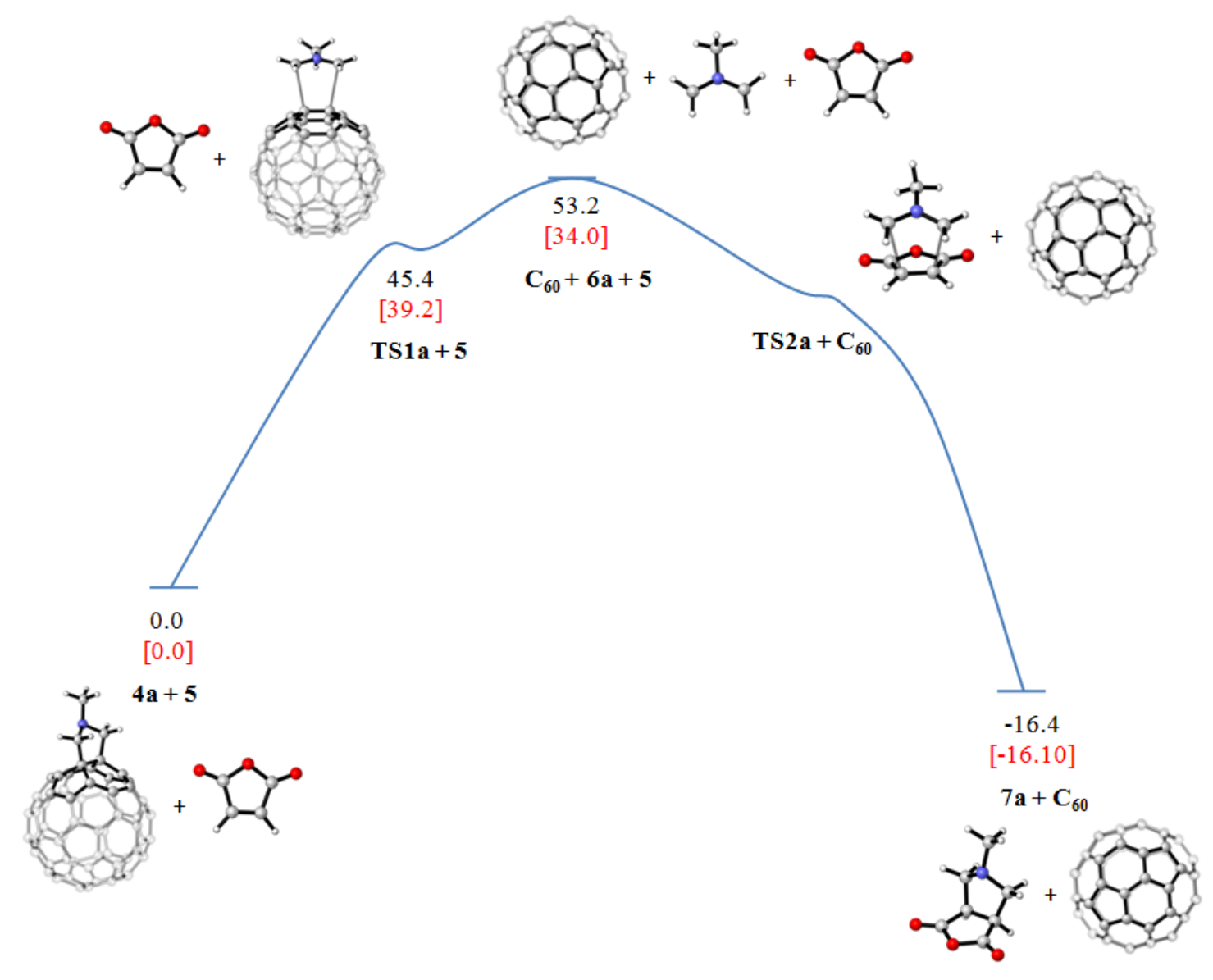

Figure 3. ONIOM2(B3LYP/6-31G(d):SVWN/STO-3G) reaction energy profile (Gibbs free energies at $298 \mathrm{~K}$ in square brackets and red color) for the retro-cycloaddition reaction of the $\mathrm{N}$ methylpyrrolidino[60]fullerene in the presence of maleic anhydride. All values are taken from ref. 12. H atoms, and coloured and dark-grey atoms constitute the layer treated at a high level in the ONIOM approach.

The same mechanism has been explored for the nitrile imine case. Figure 4 contains the relative energies and the Gibbs free energies of the TSs and products of each step of the reaction. The retrocycloaddition reaction $(\mathbf{4 b}+\mathbf{5} \rightarrow \mathbf{C} 60+\mathbf{6 b}+\mathbf{5})$ is also highly endothermic with a reaction energy of $45.4 \mathrm{kcal} \mathrm{mol}^{-1}$ and an activation barrier of $46.7 \mathrm{kcal} \mathrm{mol}^{-1}$. Gibbs free energies are somewhat smaller, 28.1 and $41.7 \mathrm{kcal} \mathrm{mol}^{-1}$ as expected from the fact that there is an increase in the entropy along the reaction coordinate. The reaction energy obtained in the first step of the reaction is more favorable (less endothermic) for the nitrile imine dipole (45.4 and $53.2 \mathrm{kcal} \mathrm{mol}^{-1}$ for nitrile imine and azomethine 
ylide, respectively). This lower reaction energy found is basically attributed to the highest stability of nitrile imine as compared to the reactive azomethine ylide. The much lower HOMO-LUMO gap for azomethine ylide $(3.62 \mathrm{eV})$ than for nitrile imine $(5.85 \mathrm{eV})$ provides evidence for the higher stability of nitrile imine. Although the reaction energy found for the first step of the reaction $\left(\mathbf{4 b}+\mathbf{5} \rightarrow \mathbf{C}_{\mathbf{6 0}}+\mathbf{6 b}+\right.$ 5) is more favorable for the case of nitrile imine, the activation barrier is $1.5 \mathrm{kcal} \mathrm{mol}^{-1}$ (or $2.5 \mathrm{kcal} \mathrm{mol}^{-1}$ in terms of Gibbs free energies) higher than for azomethine ylide. The latter difference computed from single point energy calculations at the B3LYP/6-31G(d) level using the optimized ONIOM geometries (i.e. B3LYP/6-31G(d)//ONIOM(B3LYP/6-31G(d):SVWN/STO-3G)) is $0.9 \mathrm{kcal} \mathrm{mol}^{-1}$. Although the energy differences found are very low, there is a slight preference for the retro-cycloaddition for the azomethine ylide case, which is indeed in accordance with experimental findings. Figure 5 shows the optimized structures for the TSs corresponding to the retro-cycloaddition reaction in the case of azomethine ylide (TS1a) and nitrile imine (TS1b). In both cases the TSs structures are concerted. However, TS1a is almost synchronous whereas TS1b is clearly asynchronous as expected from symmetry considerations. The $\mathrm{C}-\mathrm{C}$ bond distances of those bonds being broken are longer in TS1a (2.71 $\AA$ ) than in TS1b $(2.59 / 2.20 \AA)$ as could be anticipated from the Hammond's postulate. ${ }^{19}$ 


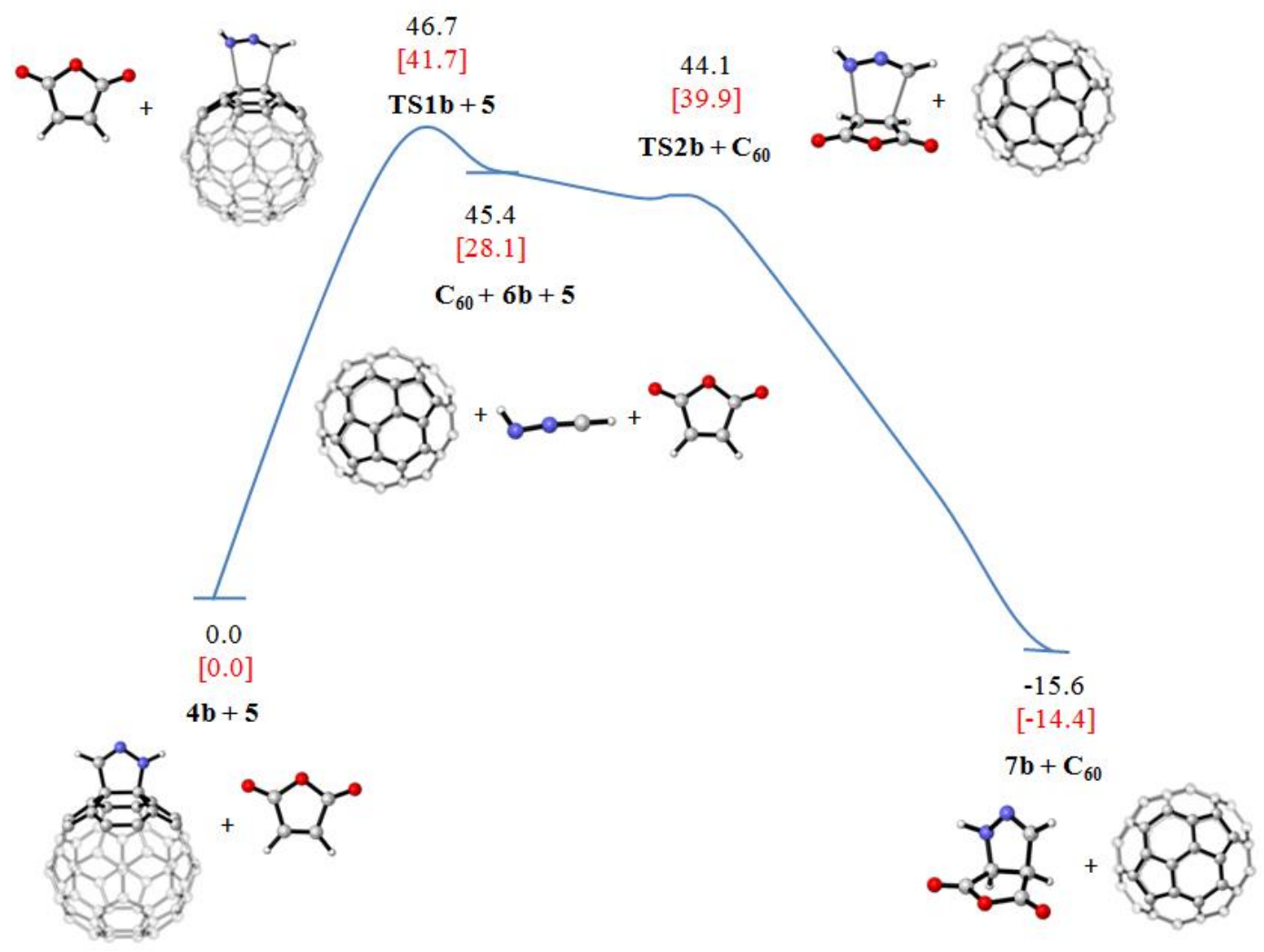

Figure 4. ONIOM2(B3LYP/6-31G(d):SVWN/STO-3G) reaction energy profile (Gibbs free energies at $298 \mathrm{~K}$ in square brackets and red color) for the retro-cycloaddition reaction of pyrazolino[60]fullerene in the presence of maleic anhydride. $\mathrm{H}$ atoms, and coloured and dark-grey atoms constitute the layer treated at a high level in the ONIOM approach.

Finally, nitrile imine reacts with maleic anhydride giving the cycloaddition product $7 \mathbf{b}\left(\mathbf{C}_{60}+\mathbf{6 b}+\mathbf{5}\right.$ $\left.\rightarrow \mathbf{C}_{60}+\mathbf{7 b}\right)$. The TS involving the formation of this product has a relative energy of $44.1 \mathrm{kcal} \mathrm{mol}^{-1}$ which is lower in energy than the previous intermediates $\left(\mathbf{C}_{\mathbf{6 0}}+\mathbf{6 b}+\mathbf{5}\right)\left(45.4 \mathrm{kcal} \mathrm{mol}^{-1}\right)$. Although a minimum structure should be found between these two stationary points, we were unable to locate any intermediate in this extremely flat region of the potential energy surface. The intrinsic reaction coordinate (IRC) has been performed to ensure that the TS found connects with the expected product (7b). 
The overall reaction $\left(\mathbf{4 b}+\mathbf{5} \rightarrow \mathbf{C}_{\mathbf{6 0}}+\mathbf{7 b}\right)$ is exothermic by $-15.6 \mathrm{kcal} \mathrm{mol}^{-1}$ (or by $-14.4 \mathrm{kcal} \mathrm{mol}^{-1}$ in terms of Gibbs free energies). However, the final reaction energy found for azomethine ylide was slightly more favorable $\left(-16.4 \mathrm{kcal} \mathrm{mol}^{-1}\right)$. The reaction energies computed with single point energy calculations at the B3LYP/6-31G(d) level using the optimized ONIOM geometries (i.e. B3LYP/631G(d)//ONIOM(B3LYP/6-31G(d):SVWN/STO-3G)) are -20.6 and -21.3 $\mathrm{kcal} \mathrm{mol}^{-1}$ for the nitrile imine and azomethine ylide, respectively. B3LYP results do also support that the retro-Prato reaction is slightly more favored than the nitrile imine retro-cycloaddition reaction.

These results show that the retro-cycloaddition reaction for nitrile imine is slightly less favorable than for azomethine ylide. The difference in reactivity observed experimentally is basically attributed to the highest (Gibbs free) energy required to surmount the TS that involves the formation of the dipole (first step of the reaction). The retro-cycloaddition of azomethine ylide does not only present a lower activation barrier, but also a slightly more favorable reaction energy for the whole process.

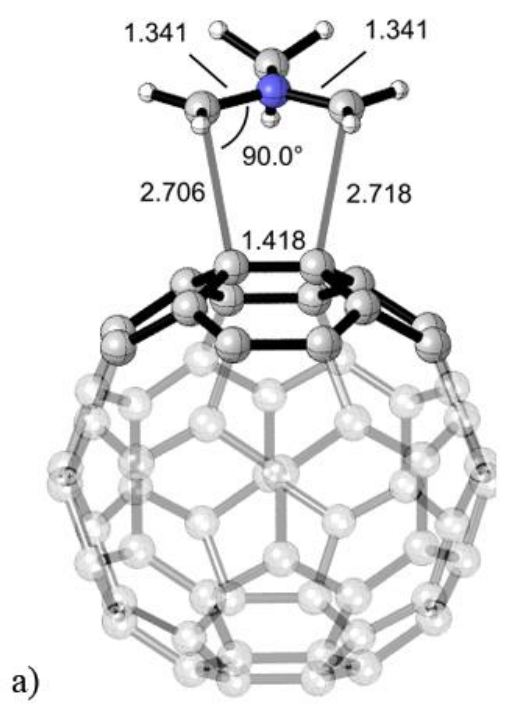

b)

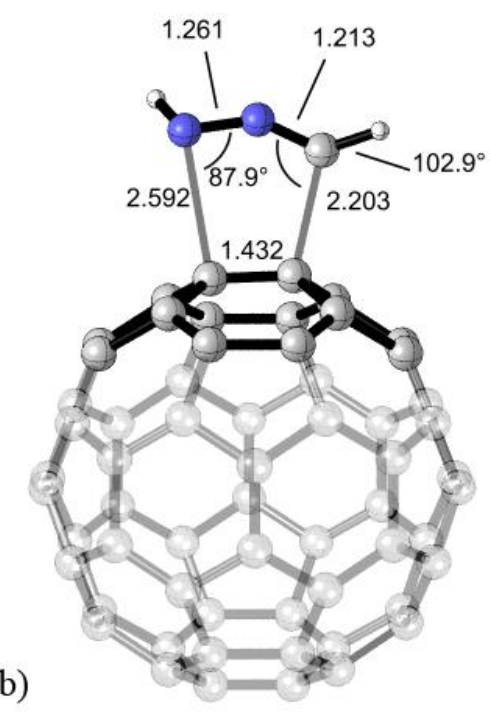

Figure 5. Optimized structures (ONIOM2(B3LYP/6-31G(d):SVWN/STO-3G)) for a) TS1a and b) TS1b with the most relevant distances and angles (in $\AA$ and in degrees). The low level of the ONIOM approach is constituted by the transparent atoms. $\mathrm{H}$ atoms, and coloured and dark-grey atoms constitute the layer treated at a high level in the ONIOM approach. 


\section{Summary and conclusions}

In summary, we have studied the retro-cycloadition process in a new family of fullerene dimers linked through 2-pyrazolino-pyrrolidino bridges (1a-c). According to the experimental findings, dimers 1a-c undergo an efficient retro-Prato (retro-cycloaddition on the pyrrolidine ring) reaction under the experimental conditions of this study. In contrast, the retro-cycloaddition reaction of 2pyrazolinofullerenes is less favored under these conditions. We have observed experimental evidences that support these conclusions, which are also in good agreement with the theoretical predictions.

These studies on the retro-cycloaddition processes are of interest since the thermal and chemical stability of fullerene derivatives is a critical issue for their applications in molecular electronics and, in particular, in the development of photovoltaic devices where fullerene cycloadducts are the materials of choice as electron acceptors in the construction of bulk heterojunction solar cells. ${ }^{20}$ Since light and heat are key parameters in photovoltaic cells, a better knowledge on their influence in the stability of modified fullerenes can help in achieving a better understanding of aspects such as morphology, charge transport and efficiency in these devices.

\section{Experimental Section}

General procedure for the retrocycloaddition experiments:

All the reactions were monitored by HPLC (Cosmosil Buckyprep column, $4.6 \mathrm{~mm}$ (i.d.) F $250 \mathrm{~mm}$; toluene, flow rate: $1 \mathrm{mLmin}^{-1}$ ). Retention times: $13.2 \mathrm{~min}$. for $\mathrm{C}_{70}, 8.5 \mathrm{~min}$ for $\mathrm{C}_{60}$.

Experiment $o$-DCB-24h.: In a typical experiment, compound 1a $(0.005 \mathrm{~mol})$,$) was heated at reflux in$ $o$-DCB $(5 \mathrm{~mL})$.

Experiment MA-24h.: Compound 1a-c (0.005 mol) and maleic anhydride $(0.016 \mathrm{mmol})$, were heated at reflux in $o$-DCB $(5 \mathrm{~mL})$. 
Experiment $\mathrm{CuTf}_{2}-24$ h.: Compound 1a $(0.005 \mathrm{~mol})$ and copper (II) triflate $(0.005 \mathrm{mmol})$ were heated at reflux in $o-\mathrm{DCB}(5 \mathrm{~mL})$.

Experiment MA-CuTf $2-24$ h.: $1 \mathbf{a}(0.005 \mathrm{~mol})$, maleic anhydride $(0.016 \mathrm{mmol})$, and copper (II) triflate $(0.005 \mathrm{mmol})$ were heated at reflux in $o$-DCB $(5 \mathrm{~mL})$.

Full geometry optimizations have been carried out with the two-layered ONIOM approach ${ }^{21,22}$ using the Gaussian 03 program. ${ }^{23}$ The density functional theory (DFT) SVWN method ${ }^{24,25}$ together with the standard STO-3G basis set ${ }^{26}$ was used for the low level calculations and the hybrid density functional B3LYP method ${ }^{27}$ with the standard 6-31G(d) basis $\operatorname{set}^{28}$ was employed for the high level system. The latter ONIOM methodology was recently shown to give accurate results close to the full B3LYP (high level method) calculations for studying cycloaddition reactions in fullerene derivatives. ${ }^{29}$ All systems were treated with the spin-restricted formalism. The choice of DFT methods was based on previous studies which showed that DFT (and in particular B3LYP together with 6-31G (d) basis set) gives accurate descriptions of the reaction mechanism of pericyclic reactions. ${ }^{30}$ Hessians were computed to determine the nature of stationary points (one or zero imaginary frequencies for transition states and minima, respectively) and to calculate unscaled zero-point energies (ZPEs) as well as thermal corrections and entropy effects using the standard statistical-mechanics relationships for an ideal gas from which Gibbs free energies have been calculated at $298 \mathrm{~K}^{31}$

Acknowledgments This work was supported by the MEC of Spain (projects CTQ2008-00795, CTQ2008-03077 and Consolider-Ingenio 2010C-07-25200), and the CAM (project P-PPQ-0002250505) the DIUE of the Generalitat de Catalunya (project 2009SGR637), and the ESF (project 05-SONSFP-021). JLD thanks the MICINN for a Ramón y Cajal Fellowship, co-financed by the EU Social Funds. SO is grateful to the Spanish MEC for a research grant. 
Supporting Information Available: (ONIOM2(UB3LYP/6-31G(d):SVWN/STO-3G)) optimized

cartesian XYZ coordinates of all analyzed species and MS-MALDI spectra of the three dimers. This material is available free of charge via the Internet at http://pubs.acs.org

\section{References}

1 Kroto, H. W.; Heath, J. R.; O’Brien, S. C.; Curl R. F. and Smalley, R. E. Nature 1985, 318, 162.

2 (a) For a recent review, see: Delgado, J. L.; Herranz, M. A.; Martín, N. J. Mater. Chem. 2008, 18, 1417. (b) Carbon Nanotubes and Related Structures: New Materials for the Twenty-First Century; Harris, P., Ed.; Cambridge University Press: Cambridge, 2001. (c) Reich, S.; Thomsen, C.; Maultzsch, J. Carbon Nanotubes: Basic Concepts and Physical Properties; VCH: Weinheim, Germany, 2004. (d) Acc. Chem. Res. 2002, 35 (Special Issue), 1997. (e) Akasaka,T.; Nagase, S. Eds., Endofullerenes: A New Family of Carbon Clusters, Kluver Academic Publishers, Dordrecht, The Netherlands, 2002.

3 (a) Hirsch A. The Chemistry of Fullerenes, Wiley-VCH, Weinheim, Germany, 2005. (b) Fullerenes: From Synthesis to Optoelectronic Properties; Guldi, D. M.; Martín, N., Eds.; Kluwer Academic Publishers: Dordrecht, The Netherlands, 2002. (c) Taylor, R. Lecture Notes on Fullerene Chemistry: A Handbook for Chemists, Imperial College Press, London, 1999. (d) Langa, F.; Nierengarten, J.-F. Eds., Fullerenes. Principles and Applications, RSC, Cambridge, UK, 2007

4 (a) Martín, N. Chem Commun. 2006, 2093. (b) Martín, N.; Altable, M.; Filippone, S.; MartínDoménech, A. Synlett 2007, 3077.

5 a) Martín, N.; Altable, M.; Filippone, S.; Martín-Doménech, A.; Echegoyen, L.; Cardona, C. M. Angew. Chem. Int. Ed. 2006, 45, 110. b) Lukoyanova, O.; Cardona, C. M.; Echegoyen, L.; Altable, M.; Filippone, S.; Martín Doménech, Á.; Martín, N. Angew. Chem. Int. Ed. 2006, 45, 7430. c) For a retrocycloaddition on SWCNTs, see: Bruneti, F. G.; Herrero, M. A.; Muñoz, J. M.; Giordani S.; Diaz-Ortiz, A.; Filippone, S.; Ruaro, G.; Meneghetti, M.; Prato, M.; Vázquez, E. J. Am. Chem. Soc. 2007, 129, 14580. 
6 (a) Martín, N.; Altable, M.; Filippone, S.; Martín-Doménech, A.; Martínez-Alvarez, R.; Suarez, M.;

Plonska-Brzezinska, M. E.; Lukoyanova, O.; Echegoyen, L. J. Org. Chem. 2007, 72, 3840. (b) Da Ros, T.; Prato, M.; Novello, F.; Maggini, M.; De Amici, M.; De Micheli, C. Chem. Commun. 1997, 59. (c) Da Ros, T.; Prato, M.; Lucchini, V. J. Org. Chem. 2000, 65, 4289.

7 (a) Delgado, J.L.; Cardinali, F.; Espíldora, E., Torres, M.R.; Langa, F. and Martín N., Org. Lett 2008., 10, 3705. (b) Delgado, J. L.; Oswald, F.; Cardinali, F.; Langa, F.; Martín, N. J. Org. Chem. 2008, 73 (8), 3184.

8 Delgado, J. L.; Espíldora, E.; Liedtke, M.; Sperlich, A.; Rauh, D.; Baumann, A.; Deibel, C.; Dyakonov, V. and Martín, N., Chem. Eur. J., in press.

9 (a) Maggini, M; Scorrano, G. and Prato, M., J. Am. Chem. Soc. 1993; 115(21); 9798. (b) Prato, M. and Maggini, M. Acc. Chem. Res. 1998, 31, 519. (c) Tagmatarchis, N. and Prato, M. Synlett 2003, 768.

10 (a) Muthu, S.; Maruthamuthu, R.; Ragunathan, P.R.; Vasudeva, P.R. and Rao, C.K., Tetrahedron Lett. 1994, 35, 1763. (b) Matsubara, Y.; Tada, H.; Nagase, S.; Yoshida, Z.; J. Org. Chem. 1995, 60, 5372. (c) Langa, F.; Oswald, F. C. R. Chimie 2006, 9, 1058. (d) Delgado, J.L.; de la Cruz, P.; LópezArza, V. and Langa, F., Tetrahedron Lett. 2004, 45, 1651. (e) Langa, F.; de la Cruz, P.; Espildora, E.; de la Hoz, A.; Bourdelande, J. L.; Sanchez, L.; Martín, N., J. Org. Chem. 2001; 66, 5033.

11 (a) Budzikiewicz, H.; Djerassi, C.; Williams, D. H. Mass Spectrometry of Organic Compounds, Holden Day, San Francisco, 1967; (b) McLafferty, F. W.; Turecek, F. Interpretation of Mass Spectra, University Science Books, Mill Valley, CA, 1993.

12 Filippone, S.; Izquierdo-Barroso, M.; Martín-Domenech, A.; Osuna, S.; Solà, M.; Martín, N. Chem. Eur. J. 2008, 14, 5198.

13 Kametani, T.; Fukumoto, K. Acc. Chem. Res. 1976, 9, 319 
14 Biemann, K. In Mass Spectrometry-Organic Chemical Applications; McGraw-Hill: New York, 1962.

15 (a) Turecek, F.; Hanus, V. Mass Spectrom. Rev. 1984, 3, 85. (b) Szmigielski, R.; Danikiewicz, W.; Dolatowska, K.; Wojciechowski, K. Int. J. Mass Spectrom. 2006, 248, 148. (c) Meurer, E. C.; Sparrapan, R.; Eberlin, M. N. J. Mass Spectrom. 2003, 38, 1075. (d) Ovcharenko, V. V.; Pihlaja, K.; Stajer, G. J. Am. Soc. Mass Spectrom. 2001, 12, 1011.

16 Darwish, A. D.; Avent, A.G.; Birkett, P. R.; Kroto, H. W.; Taylor, R.; Waltom, D. R. M. J. Chem. Soc. Perkin Trans 2, 2001, 1038 and references therein.

17 (a) Kotsiris, S. G.; Vasilév, Y. V.; Streletskii, A. V.; Han, M.; Mark, L. P.; Boltalina, O. V.; Chronakis, N.; Orfanopoulos, M.; Hungerbuhler, H.; Drewello, T. Eur. J. Mass. Spectrom. 2006, 12, 397 (b) Kozlovski, V.; Brusov, V.; Sulimenkov, I.; Pikhtelev, A.; Dodonov, A. Rapid. Commun. Mass. Spectrom. 2004, 18, 780 (c) Barrow, M. P.; Feng, X.; Wallace, J. I.; Boltalina, O. V.; Taylor, R.; Derrick, P. J.; Drewello, T. Chem. Phys. Lett. 2000, 330, 267 (d) Illescas, B. M.; Martinez-Alvarez, R.; Fernandez-Gadea, J. and Martín, N., Tetrahedron 2003, 59(34), 6569.

18 Works currently in progress demonstrate that under ESI conditions substituted N-benzoyl pyrrolidinofullerenes undergo the loss of the benzoyl group instead the retro-cycloaddition process. In contrast, the spectrometric fragmentation of substituted pyrazolinofullerenes affords $\mathrm{C}_{60}$ as result of a retro-cycloaddition reaction.

19 Hammond, G. S. J. Am. Chem. Soc. 1955, 77, 334.

20 (a) Thompson, B.C. and Fréchet, J.M.J., Angew. Chem. Int. Ed. 2008, 47, 58. (b) Gunes, S.; Neugebauer, H.; Sariciftci, N. S., Chem. Rev. 2007; 107(4), 1324. (c) Riedel, I.; von Hauff, E.; Parisi, J.; Martin, N.; Giacalone, F. and Dyakonov, V., Adv. Funct. Mater. 2005, 15, 1979.

21 Svensson, M.; Humbel, S.; Froese, R. D. J.; Matsubara, T.; Sieber, S.; Morokuma, K. J. Phys. Chem. 1996, 100, 19357. 
22 Dapprich, S.; Komáromi, I.; Byu, K. S.; Morokuma, K.; Frisch, M. J. J. Mol. Struct. (Theochem) 1999, 461-462, 1.

23 Frisch, M. J.; Trucks, G. W.; Schlegel, H. B.; Scuseria, G. E.; Robb, M. A.; Cheeseman, J. R.; Montgomery Jr., J. A.; Vreven, T.; Kudin, K. N.; Burant, J. C.; Millam, J. M.; Iyengar, S. S.; Tomasi, J.; Barone, V.; Mennucci, B.; Cossi, M.; Scalmani, G.; Rega, N.; Petersson, G. A.; Nakatsuji, H.; Hada, M.; Ehara, M.; Toyota, K.; Fukuda, R.; Hasegawa, J.; Ishida, M.; Nakajima, T.; Honda, Y.; Kitao, O.; Nakai, H.; Klene, M.; Li, X.; Knox, J. E.; Hratchian, H. P.; Cross, J. B.; Bakken, V.; Adamo, C.; Jaramillo, J.; Gomperts, R.; Stratmann, R. E.; Yazyev, O.; Austin, A. J.; Cammi, R.; Pomelli, C.; Ochterski, J. W.; Ayala, P. Y.; Morokuma, K.; Voth, G. A.; Salvador, P.; Dannenberg, J. J.; Zakrzewski, G.; Dapprich, S.; Daniels, A. D.; Strain, M. C.; Farkas, O.; Malick, D. K.; Rabuck, A. D.; Raghavachari, K.; Foresman, J. B.; Ortiz, J. V.; Cui, Q.; Baboul, A. G.; Clifford, S.; Cioslowski, J.; Stefanov, B. B.; Liu, G.; Liashenko, A.; Piskorz, P.; Komaromi, I.; Martin, R. L.; Fox, D. J.; Keith, T.; Al-Laham, M. A.; Peng, C. Y.; Nanayakkara, A.; Challacombe, M.; Gill, P. M. W.; Johnson, B.; Chen, W.; Wong, M. W.; Gonzalez, C.; Pople, J. A.; Gaussian 03, Revision C.01 ed.; Gaussian, Inc.: Pittsburgh, PA, 2003.

24 Slater, J. C. Quantum Theory of Molecules and Solids; McGraw-Hill: New York, 1974; Vol. 4.

25 Vosko, S. H.; Wilk, L.; Nusair, M. Can. J. Phys. 1980, 58, 1200.

26 Hehre, W. J.; Stewart, R. F.; Pople, J. A. J. Chem. Phys. 1969, 51, 2657.

27 (a) Becke, A. D. J. Chem. Phys. 1993, 98, 5648-5652. (b) Lee, C.; Yang, W.; Parr, R. G. Phys. Rev. B 1988, 37, 785. (c) Stephens, P. J.; Devlin, F. J.; Chabalowski, C. F.; Frisch, M. J. J. Phys. Chem. 1994, $98,11623$.

28 (a) Hehre, W. J.; Ditchfield, R.; Pople, J. A. J. Chem. Phys. 1972, 56, 2257. (b) Hariharan, P. C.; Pople, J. A. Theor. Chim. Acta 1973, 28, 213.

29 Osuna, S.; Morera, J.; Cases, M.; Morokuma, K.; Solà, M. J. Phys. Chem. A, 2009, 113, 9721. 
30 (a) Cases, M.; Duran, M.; Mestres, J.; Martín, N.; Solà, M. J. Org. Chem. 2001, 66, 433. (b) Di Valentin, C.; Freccero, M.; Gandolfi, R.; Rastelli, A. J. Org. Chem. 2000, 65, 6112. (c) Dinadayalane, T. C.; Vijaya, R.; Smitha, A.; Sastry, G. N. J. Phys. Chem. A 2002, 106, 1627. (d) Freccero, M.; Gandolfi, R.; Sarzi-Amade, M.; Rastelli, A. J. Chem. Soc. Perkin Trans. 2 1998, 2413. (e) Goldstein, E.; Beno, B.; Houk, K. N. J. Am. Chem. Soc. 1996, 118, 6036. (f) Isobe, H.; Yamanaka, S.; Yamaguchi, K. Int. J. Quant. Chem. 2003, 95, 532. (g) Wiest, O.; Houk, K. N. Top. Curr. Chem. 1996, 183, 1. (h) Wiest, O.; Houk, K. N.; Black, K. A.; Thomas, B. J. Am. Chem. Soc. 1995, 117, 8594.

31 Atkins, P.; De Paula, J. in Physical Chemistry, Oxford University Press, Oxford, 2006. 